\title{
Gender dimorphism of white matter integrity assessed by diffusion tensor magnetic resonance imaging in abstinent alcoholic men and women
}

\author{
Kayle S Sawyer ${ }^{1,2^{*}}$, George Papadimitriou ${ }^{3}$, Susan M Ruiz ${ }^{1,2}$, Nikos Makris ${ }^{3}$, Marlene Oscar-Berman ${ }^{1,2,3}$, \\ Gordon J Harris ${ }^{4,5}$
}

From 2014 Addiction Health Services Research (AHSR) Conference

Boston, MA, USA. 15-17 October 2014

\section{Background}

Alcoholism is a debilitating disorder associated with widespread cognitive and neurological abnormalities. However, there is limited scientific literature evaluating gender-specific similarities and differences in microstructural white matter pathology associated with alcoholism. In our prior work, we used diffusion tensor magnetic resonance imaging to examine the integrity of white matter fiber tracts in the brains of abstinent alcoholic (ALC) men compared with nonalcoholic (NC) men. We found that ALC men had decreased fractional anisotropy (FA) within white matter fiber tracts connecting to frontal and limbic networks, primarily of the right hemisphere (Harris et al., 2008). In the current project, we sought to confirm our prior findings in abstinent ALC men and, additionally, examine whether different white matter abnormalities were present in abstinent ALC women.

\section{Methods}

As determined by our manual inspection, 60-direction high-quality diffusion tensor imaging images were acquired from 30 abstinent (at least 4 weeks) ALC participants (21 women) and $25 \mathrm{NC}$ controls (17 women). Tract-based spatial statistics tools included in FSL 5.0 were used to analyze a tensor model that yielded regional FA values for each participant. To examine the effects of gender, we built a 2 X 2 ANOVA design with three planned comparisons of primary interest: ALC

\footnotetext{
* Correspondence: kslays@bu.edu

'Department of Anatomy \& Neurobiology, Boston University School of Medicine, Boston, MA, 02118, USA

Full list of author information is available at the end of the article
}

group-by-gender interaction, ALC women versus NC women, and ALC men versus NC men.

\section{Results}

We observed FA deficits in ALC men relative to NC men, with a similar effect size and variability as observed in our prior study. In contrast, ALC women displayed strikingly greater FA values compared to $\mathrm{NC}$ women in widespread white matter regions, including most principal long-association fiber tracts. Also, they had greater FA for local white matter architecture in the dorsolateral and ventral prefrontal regions, as well as the sublenticular extended amygdala. When controlling for multiple comparisons, the higher FA observed in ALC women remained significant. For many regions, groupby-gender interaction effects were observed. However, likely due to the small sample sizes for men, the interaction effects did not survive threshold-free cluster enhancement, the correction procedure for multiple comparisons used in these analyses.

\section{Conclusions}

These results suggest antithetical gender abnormalities in white matter tracts of ALC brains. Whereas abstinent ALC men displayed deficits consistent with our prior study, our new findings for abstinent ALC women demonstrated increased FA values. These distinct patterns of white matter abnormalities point toward a differential underlying neural basis for gender-specific propensity and/or sequelae to long-term alcoholism, and suggest implications for further investigation of possible gender-specific approaches to prevention and treatment. 


\section{Acknowledgements}

This work was supported by funds from the National Institute on Alcohol Abuse and Alcoholism (grants R01AA07112 and K05AA00219) and the Medical Research Services of the U.S. Department of Veterans Affairs to Dr. Marlene Oscar Berman.

\section{Authors' details}

'Department of Anatomy \& Neurobiology, Boston University School of Medicine, Boston, MA, 02118, USA. 'Psychology Research Service, VA Boston Healthcare System, Jamaica Plain, MA, 02130. ${ }^{3}$ Center for Morphometric Analysis, Massachusetts General Hospital, Charlestown, MA, 02129, USA. ${ }^{4}$ Departments of Psychiatry and Neurology, Boston University School of Medicine, Boston, MA, 02118, USA. ${ }^{5}$ 3D Imaging Service, Massachusetts General Hospital, Boston, MA, 02114, USA.

Published: 20 February 2015

\section{Reference}

1. Harris GJ, Jaffin SK, Hodge SM, Kennedy DN, Caviness VS, Marinkovic K, Papadimitriou GM, Makris N, Oscar-Berman M: Frontal white matter and cingulum diffusion tensor imaging deficits in alcoholism. Alcoholism: Clin Exper Res 2008, 32(6):1001-1013.

doi:10.1186/1940-0640-10-S1-A59

Cite this article as: Sawyer et al:: Gender dimorphism of white matter integrity assessed by diffusion tensor magnetic resonance imaging in abstinent alcoholic men and women. Addiction Science \& Clinical Practice 2015 10(Suppl 1):A59.

\section{Submit your next manuscript to BioMed Central} and take full advantage of:

- Convenient online submission

- Thorough peer review

- No space constraints or color figure charges

- Immediate publication on acceptance

- Inclusion in PubMed, CAS, Scopus and Google Scholar

- Research which is freely available for redistribution

Submit your manuscript at www.biomedcentral.com/submit 